OPEN ACCESS

Edited by:

Hans-Werner Wahl,

Heidelberg University, Germany

Reviewed by:

Isabelle Albert,

University of Luxembourg, Luxembourg

Ehud Bodner,

Bar-Ilan University, Israel

*Correspondence:

Marijke Veenstra

mveen@oslomet.no

Specialty section:

This article was submitted to

Health Psychology,

a section of the journal

Frontiers in Psychology

Received: 31 May 2021 Accepted: 13 September 2021

Published: 06 October 2021

Citation:

Veenstra M, Løset GK and Daatland SO (2021) Socioeconomic Inequalities in Mortality After Age 67:

The Contribution of Psychological

Factors.

Front. Psychol. 12:717959.

doi: 10.3389/fpsyg.2021.717959

\section{Socioeconomic Inequalities in Mortality After Age 67: The Contribution of Psychological Factors}

\author{
Marijke Veenstra*, Gøril Kvamme Løset and Svein Olav Daatland \\ NOVA, Oslo Metropolitan University, Oslo, Norway
}

Diverging trends of longer lives and increased inequalities in age-at-death invite to updated research on late-life mortality. Earlier studies have identified health behavior, childhood, psychosocial, and material conditions as key determinants of life expectancy, but the role of psychological factors remains a topic of debate. The current study is framed in a life course developmental perspective and assesses the mediating role of secondary control strategies (subjective age) and primary control capacity (perceived control) to socioeconomic (wealth and education) inequality in mortality after age 67. Data are derived from the second wave of the Norwegian Life Course, Ageing and Generation study ( $N=1,432$ and age 67-85). All in all, 366 deaths were observed over a mean follow-up of 9.6years. Perceived control was measured by the Pearlin and Schooler Mastery Scale. SA was measured with proportional discrepancy scores in felt age and ideal age. Stepwise Cox proportional hazards regression analyses were conducted to analyze the relative contribution of SES (education and accumulated wealth), felt age, and ideal age discrepancies and perceived control on 11-year mortality. Findings show that lower levels of wealth and perceived control independently predict increased elderly mortality over an 11-year period. Feeling younger and smaller ideal age discrepancies are positively associated with perceived control, but do not account for additional variability in longevity among older adults. Findings add to the interdisciplinary field of socioeconomic inequalities in elderly mortality and underline the specific importance of structural conditions (wealth) and the continued importance of (perceived) primary control capacity for longevity also after age 67. Future research may assess in more detail how wealth and perceived control complement each other in contributing to healthy aging and longevity, for example, by longitudinal research including the role of significant life events in the second half of life in different welfare state contexts.

Keywords: life span developmental theory, aging, socioeconomic inequalities, mortality, perceived control, subjective age 


\section{INTRODUCTION}

Longevity increases, and larger parts of the population, in particular those with higher socioeconomic status (SES), survive to more advanced ages (Murtin et al., 2017; OECD, 2017; Kinge et al., 2019; Permanyer and Scholl, 2019). The resulting diverging trends of longer lives and increased inequalities in age-at-death have prompted recent calls for more research on factors contributing to patterns of elderly mortality, that is, patterns conditional upon survival to, for example, the standard retirement age (Abramson and Portacolone, 2017; Permanyer and Scholl, 2019; Aburto et al., 2020). Extensive research has identified childhood and material living conditions as well as behavioral and psychosocial characteristics as core determinants of (inequalities in) life expectancy (Mackenbach et al., 2019). However, the contribution of psychological factors to life span variability among older adults is still a topic of debate. Over the life course, differences in SES render differences in material and coping resources (e.g., beneficial social connections and control), thereby contributing to differential exposure to stressors and to differential vulnerability (Phelan et al., 2010). In old age, individuals from divergent backgrounds face life transitions that typically constitute moments of vulnerability, that is, declining mobility, onset of health problems, and the loss of close family members and friends (Heckhausen, 1997; Abramson and Portacolone, 2017). Examining the different, and sometimes similar, perceptions of aging and adaptation in older people may provide a powerful vantage point for understanding how psychological factors shape inequalities in elderly mortality. The current study departs from life span developmental theory (LSD; Heckhausen, 1997; Heckhausen et al., 2019), which assumes that people actively shape their own development, and examines the contribution of psychological factors, that is, perceived control and subjective age perceptions, for mortality patterns in adults aged 67 and older.

The basic assumption of LSD theory is that "individuals in general strive to maximize primary control of their environment and developmental outcomes by adapting their regulatory strategies to the opportunities and constraints encountered in a given situation" (Heckhausen et al., 2019). In this way, older adults do not qualitatively differ from younger adults but they have to strive for control in a life phase that is characterized by developmental losses more than by gains (Heckhausen et al., 2010) and where "control-enhancing experiences" get rarer and "control-restricting circumstances" increase (Wolinsky et al., 2003). This means that although striving for primary control is assumed to remain constant throughout the life course, the capacity for primary control, often proxied by measures of perceived control, tends to gradually decline in old age (Slagsvold and Sørensen, 2013; Robinson and Lachman, 2017; Heckhausen et al., 2019). Perceived control over life circumstances is also inversely distributed by social status: those with higher education or income perceive greater control (Elstad, 1998; Mirowsky and Ross, 2007). Moreover, the less advantaged are found to face declining primary control capacity earlier in life than those from more advantaged positions (Heckhausen et al., 2010). So far, some empirical evidence suggests that low socioeconomic status is related to mortality partly because people with a low socioeconomic status more often perceive low control (Bosma et al., 1999) and that those with a lower SES who do have higher levels of perceived control tend to have health and longevity similar to those with a higher SES (Lachman and Weaver, 1998; Turiano et al., 2014; Robinson and Lachman, 2017).

Higher SES is associated with greater access to resources throughout the life course, which in turn facilitates regulation of developmental trajectories, including analyzing opportunities to optimize goal choices to ensure higher control capacity. Older individuals from advantaged SES backgrounds may have multiple goal-path options to strengthen control capacity (Heckhausen et al., 2010), whereas disadvantaged individuals may have few. These different goal-path options can be grouped into primary and secondary control strategies. Primary control strategies aim at "changing the external environment in line with one's wishes," whereas secondary control processes imply "changing the self to bring oneself in line with environmental forces" (Heckhausen et al., 2019). The use of secondary control strategies, that is, selective and compensatory secondary control, tends to become more common in old age (Schulz and Heckhausen, 1996; Thompson et al., 1998; Chipperfield et al., 1999). Selective secondary control serves to enhance and maintain commitment to a feasible goal (Heckhausen et al., 2010), for example, through positive illusions about one's control potential for achieving the goal. Compensatory secondary control strategies are aimed at minimizing negative effects of loss on the individual's perceived control (Heckhausen, 1997), which can be achieved by, for example, goal disengagement or strategic social comparison (Bailis et al., 2005; Heckhausen et al., 2010).

A potentially important secondary control strategy to face challenges associated with advanced age is subjective age identification (Heckhausen, 1997; Shane et al., 2019) - the way individuals think about age and the stages of life they are in. Subjective age (SA) is a core indicator of the individual aging experience, with important anticipated consequences for successful aging in older adults (Kastenbaum et al., 1972; KleinspehnAmmerlahn et al., 2008; Kotter-Gruhn et al., 2016). SA comprises different components, including felt age and ideal age (Kastenbaum et al., 1972; Uotinen et al., 2005; Veenstra et al., 2020). Research on SA can be traced back to as far as the 1950s (Blau, 1956) and has since then consistently shown that from early middle age onwards, an increasing proportion of people feels younger than their actual age, and would like to be even younger (Barak and Stern, 1986; Montepare and Lachman, 1989; Hubley and Hultsci, 1994; Daatland, 2007). SA is therefore assumed to gain particular importance in the second half of life, where attitudes toward aging are assumed to become more self-relevant than actual age (Settersten and Mayer, 1997; Diehl et al., 2014; Kornadt et al., 2018). SA is strongly affected by age stereotypes (Levy, 2009). As people grow older, the stereotype age norms prevailing in society may make it difficult to adopt an older identity without losing a sense of continuity of the self as they are confronted with age-related physical, cognitive, and social changes (Westerhof et al., 2012; Settersten and Hagestad, 2015). Older adults who report feeling younger than their chronological age are using a 
selective secondary control strategy that enables a feeling of continuation of one's self-perception. This, in turn, may enhance vitality and resourcefulness, which increases overall perceived control capacity and encourages selective primary control striving. Empirical findings support this assumption (Shane et al., 2019) and have also shown that feeling younger is associated with reduced mortality (Uotinen et al., 2005; Kotter-Gruhn et al., 2009; Stephan et al., 2018).

Wanting to be younger than one's actual age (younger ideal age) constitutes a compensatory secondary control strategy aimed at identifying with an age that reflects desired control potential (Heckhausen, 1997). It is not uncommon for older adults to report an ideal age which is 18 to 19 years younger than one's current age (Uotinen et al., 2006; Keyes and Westerhof, 2012; Veenstra et al., 2020). However, findings from previous studies consistently show that wanting to be increasingly younger is associated with poorer health outcomes, including higher mortality (Maier and Smith, 1999; Uotinen et al., 2006; Keyes and Westerhof, 2012; Veenstra et al., 2020). A large discrepancy between ideal age and one's chronological age may arise when there is an incongruence between the aspired goal and actual constraints in opportunities to reach this goal and reflects "withdrawing effort without breaking up the motivational commitment" (Wrosch et al., 2003), "a passive reflection of failure and loss" (Heckhausen et al., 2010), and feelings of regret (Heckhausen et al., 2019). On the other hand, an ideal age close to one's actual age reflects more positive self-perceptions of aging and higher age satisfaction (Hubley and Hultsci, 1994; Kaufman and Elder, 2002). An earlier study by Levy et al. (2002) showed that individuals with positive selfperceptions of aging lived on average 7.5 years longer than individuals who had negative self-perceptions.

In sum, whereas feeling younger may serve as an adaptive selective secondary control strategy in response to aging and thus contribute to perceived control and longevity (Westerhof et al., 2014), wanting to be younger may function as a maladaptive compensatory secondary strategy (Keyes and Westerhof, 2012) associated with perceived lower control and increased mortality. SES is considered a core determinant of subjective aging through its influences on the timing of life transitions and rate of health decline (Barrett, 2003). Consequently, those with lower SES tend to adopt older age identities and to show less satisfaction with aging (Kleinspehn-Ammerlahn et al., 2008).

The present study extends existing knowledge by assessing the relative contribution of perceived control and domains of SA to socioeconomic inequalities in elderly mortality. More specifically, we argue that subjective age perceptions are important secondary control strategies for primary control capacity (perceived control), which both are influenced by levels of SES and, this way, mediate the association of SES with longevity in older adults.

\section{MATERIALS AND METHODS}

\section{Study Procedure and Participants}

We used data from the second wave of the longitudinal Norwegian Life course, Ageing and Generation study (NorLAG), which collects data from a nationwide, population-based, and stratified sample of adults born between 1922 and 1966 (Veenstra et al., 2021). NorLAG combines survey data linked to data from national public registers. The second wave (NorLAG2) was conducted in 2007-2008, and the full sample includes 9,238 respondents (response rate $61 \%$ ), of whom 1,673 persons are 67 years and older. Survey data collection consisted of an initial telephone interview followed by a postal questionnaire. As is common in most longitudinal studies, selective attrition is a challenge also in NorLAG: Respondents with higher education and good self-rated health are more inclined to participate. We refer to NorLAG's cohort profile (Veenstra et al., 2021) for more detailed information about design, samples, and response rates. Study participation and linkages to register data are based on informed consent. All participants are listed in the Population Register that provides information on all-cause mortality up to the start of the data collection for the third wave of NorLAG (March 31st, 2017). The analyses in the current study are based on complete data, including respondents who returned the postal questionnaire and had valid answers on SA and perceived control $(N=1,432)$. Compared to those who only participated in the telephone interview, those who returned the postal questionnaire were higher educated $\left(\chi^{2}=17.4\right.$; $d f=2 ; p<0.001)$, somewhat younger $(t=3.10 ; p=0.002)$, somewhat more likely to have good/excellent self-rated health $\left(\chi^{2}=4.2\right.$; $d f=1 ; p=0.041)$, and to be female $\left(\chi^{2}=3.9 ; d f=1 ; p=0.049\right)$. Mortality rates did not differ significantly between these two groups $\left(\chi^{2}=1.9 ; d f=1 ; p<0.158\right)$.

\section{Measures}

\section{Survival Time}

We measure survival time as year of baseline interview in NorLAG2 (2007 or 2008) to the year of either death or end of follow-up (March 2017). Ninety-five percent of the sample was interviewed in 2007. Due to reasons of confidentiality, only the year of death was included in NorLAG. Two respondents died during the same year they were interviewed. Survival time for these persons was set to 0.5 .

\section{Socioeconomic Status}

SES is assessed by educational attainment and accumulated wealth at the time of the interview. Level of education was derived from the public registries (Norwegian Standard Classification of Education Revised 2000) and grouped into three categories: compulsory (1), secondary (2), and tertiary education (3). Data on taxable gross wealth are available through the linkages with the tax register and comprises taxable real capital and taxable gross financial capital rounded to the nearest $10,000 \mathrm{NOK}$. Wealth data were grouped into quartiles $<280,000$

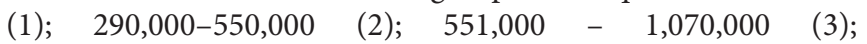
and $>1,070,000$ (4).

\section{Perceived Control}

Perceived control is a assumed to be a proxy for (subjective) control capacity and is measured in NorLAG2 through the self-administered questionnaire with the Pearlin and Schooler's 
Personal Mastery Scale (PMS; Pearlin and Schooler, 1978). The PMS measures the self-belief or conviction that one is able to control the important circumstances that are currently impinging on one's life (Pearlin and Schooler, 1978; Pearlin et al., 1981). The PMS consists of seven items, of which two are positively phrased. Examples of items are as follows: "I have little control over the things that happen to me"; "I can do just about anything I really set my mind to"; "There is really no way I can solve some of the problems I have"; and "What happens to me in the future mostly depends on me." Responses are measured on a 5-point Likert scale (1 "fully agree" and 5 "fully disagree"), which are recoded and aggregated into a single total sum score, ranging from 5 to 35 , with higher scores indicating stronger feelings of sense of control. Cronbach's alpha for the PMS in the current study was 0.70 indicating satisfactory reliability.

\section{Subjective Age (SA)}

The items measuring felt age and ideal age are part of the postal questionnaire. Felt age is assessed with the item: "What age do you usually feel?" Ideal age is measured by asking: "If you could choose your age, what age would you like to be?" In both instances, respondents wrote down the age in number of years, which provides information on the direction as well as the magnitude of the subjective age discrepancy. Information on respondents' chronological age at time of interview is derived from the public registers and linked to the survey data. We calculated the proportional discrepancy score by subtracting felt age from chronological age (chronological age - felt age) and divide this by chronological age. Proportional discrepancy scores for ideal age are calculated in the same manner. A negative value thus indicates older subjective ages, whereas positive values indicate that a person feels (felt age) or wants to be (ideal age) younger than his or her chronological age.

\section{Confounders}

In addition to age at time of baseline interview and gender $(0=$ male; $1=$ female $)$, we control for physical health limitations $(0=$ no; $1=$ yes $)$, living with a partner/spouse $(0=$ no; $1=$ yes $)$, and smoking cigarettes $(0=$ no; $1=$ yes). All confounders refer to baseline measures in NorLAG2. Adjusting for these variables is necessary because they have known associations with SES and perceived control, as well as mortality (Mackenbach et al., 2019).

\section{Statistical Analyses}

We use summary statistics ( $t$ tests, chi-square statistics) and bivariate correlations (Pearson's $r$ ) to describe the central study variables and their relationships. Associations of baseline measures with mortality endpoints are assessed using stepwise Cox proportional hazards regression. Hazard ratios (HR) and their 95\% confidence interval (CI) are used to summarize the associations. We compute standardized scores (Z-scores) for the PMS and the two domains of SA. This way, coefficients can be interpreted as change in standard deviations (SD). We start with computing the unadjusted (bivariate) HRs for the core variables of interest. The first model (Model 1) in the stepwise Cox proportional hazards regression is the baseline model with the basic demographic variables: age and gender. The second model adds markers of SES: wealth and level of education. In the third model, we also include the two measures of SA (felt age and ideal age discrepancies) and in the fourth model perceived control as measured by the PMS is added. The full model (Model 5) includes other known risk factors (health, partner status, and health behavior) as well. To estimate how much the different steps contributed to explained variance, we use the generalized R-squared, which produces a pseudo$\mathrm{R}$-squared, calculated as $1-\exp [(\chi \mathrm{LR} 2) / \mathrm{n}]$, where $(\chi \mathrm{LR} 2)$ is the chi-square statistic for the likelihood ratio test for the model, and $\mathrm{n}$ is the total number of cases. For all statistical tests, we apply a critical value (a) of $5 \%$.

As a robustness check, we conducted similar analyses with logistic regression models with survival status as dichotomous outcome, thereby ignoring the information on time to death. These analyses (available upon request) yielded similar results, and we therefore only report the findings from the Cox regression analyses.

\section{RESULTS}

During a mean follow-up time of $9.6(S D=2.7)$ years, 366 deaths from all causes occurred, corresponding to 25.6 percent of the sample of persons aged 67 years and older. A description of the characteristics of the full sample and across mortality status is given in Table 1.One out of four of the respondents had tertiary (higher) education, but a significantly greater share of those who died over the follow-up were in the group with primary education (28.1 percent). Similarly, those who had died were less likely to be from the highest wealth quartile (19.7 percent) compared to those who were alive at follow-up (26.7 percent). Average perceived control as measured by the PMS was significantly lower among those who had died (23.0 versus 25.1). Proportional differences scores for felt age and ideal age were 0.12 and 0.33 , respectively. This implies that, on average, individuals felt 12 percent younger and had an ideal age which was 33 percent younger relative to their chronological age. People who died felt on average 8.2 years younger than their actual age, compared to 9.4 years among those who survived. These differences were statistically significant and corresponded to proportional discrepancy scores of 0.11 and 0.13 . Moreover, people who had died during follow-up had, on average, an ideal age that was 26.9 years younger than their chronological age, which corresponded to a proportional discrepancy score of 0.36 . Those who survived had an average ideal age discrepancy of 23.7, corresponding to a proportional discrepancy score of 0.33 . These differences in ideal age discrepancies across mortality status were statistically significant as well. In addition, those who died during follow-up were more likely to be men (61.5 percent), have physical health problems (37.7 percent), smoke cigarettes (21.0 percent), and less likely to live with a partner at baseline (59.3 percent). 
TABLE 1 | Baseline characteristics of the study sample according to survival status at the end of follow-up.

\begin{tabular}{|c|c|c|c|}
\hline Variables & $\begin{array}{l}\text { People who } \\
\text { survived }\end{array}$ & Deceased & Total sample \\
\hline$N$ & 1,066 & 366 & 1,432 \\
\hline Women (\%)*** & 52.3 & 38.5 & 48.7 \\
\hline Chronological age, mean (SD)*** & $72.2(4.3)$ & $75.5(5.1)$ & $73.1(4.7)$ \\
\hline \multicolumn{4}{|l|}{ Education (\%)* } \\
\hline Primary & 22.8 & 28.1 & 24.2 \\
\hline Secondary & 50.2 & 51.6 & 50.6 \\
\hline Tertiary & 27.0 & 20.2 & 25.3 \\
\hline \multicolumn{4}{|l|}{ Wealth in NOK - quartiles* } \\
\hline$<280,000$ & 24.5 & 27.6 & 25.3 \\
\hline $290,000-550,000$ & 23.7 & 27.3 & 24.7 \\
\hline $560,000-1,070,000$ & 25.0 & 25.4 & 25.1 \\
\hline$>1,070,000$ & 26.7 & 19.7 & 24.9 \\
\hline Perceived control, mean (SD)*** & $25.1(5.0)$ & $23.0(5.3)$ & $24.6(5.1)$ \\
\hline Felt age discrepancy, mean (SD)* & $9.4(8.8)$ & $8.2(9.2)$ & $9.1(9.0)$ \\
\hline Ideal age discrepancy, mean (SD)** & $23.7(16.2)$ & $26.9(17.7)$ & $24.5(16.7)$ \\
\hline $\begin{array}{l}\text { Felt age proportional discrepancy, } \\
\text { mean (SD)*** }\end{array}$ & $0.13(0.12)$ & $0.11(0.12)$ & $0.12(0.12)$ \\
\hline $\begin{array}{l}\text { Ideal age proportional } \\
\text { discrepancy, mean (SD)*** }\end{array}$ & $0.33(0.22)$ & $0.36(0.23)$ & $0.33(0.22)$ \\
\hline Physical health problems (\%)*** & 20.6 & 37.7 & 25.0 \\
\hline Living with a partner (\%)** & 67.9 & 59.3 & 65.7 \\
\hline Smoking cigarettes (\%)** & 14.1 & 21.0 & 15.9 \\
\hline
\end{tabular}

$* p<0.05 ; * * p<0.01 ; * * * p<0.001$.

Table 2 provides an overview of the bivariate correlations between the study variables. Mortality was statistically significantly associated with all study variables. Strongest correlations were with chronological age $(r=0.30)$, and the weakest correlations were with proportional discrepancy scores for ideal age $(r=0.06)$. SES was significantly, although weakly, correlated with mortality, with $r=0.08$ and $r=0.07$ for educational attainment and wealth, respectively. The positive correlation of ideal age discrepancy scores with mortality implies that wanting to be increasingly younger is associated with higher mortality, whereas the negative correlation of felt age discrepancy scores with mortality indicates that feeling younger than one's actual age is associated with reduced mortality. As anticipated, a perceived higher control was associated with less mortality $(r=-0.18)$.

Higher education was moderately associated with higher wealth $(r=0.31)$. Both markers of SES were significantly and positively associated with perceived control. The bivariate correlations with proportional discrepancy scores for felt age were, however, not statistically significant. Only the association between education and ideal age discrepancies was statistically significant $(r=-0.06)$, indicating that those with higher education had smaller ideal age discrepancies. Larger felt age discrepancies were associated with higher levels of perceived control $(r=0.12)$, whereas larger ideal age discrepancies were associated with perceived lower control $(r=-0.08)$. Respondents reporting larger felt age discrepancies (i.e., feeling younger than their actual age) also reported larger ideal age discrepancies (i.e., wanting to be younger than one's actual age), but correlations between these two aspects of SA were relatively modest $(r=0.18)$. The two aspects of SA were relatively weakly correlated with the other study variables. Perceived control was significantly correlated with all study variables except for smoking cigarettes.

The Cox regression (Table 3 Unadjusted HR) showed that one increasing level of education or one higher quartile of wealth was associated with a 12-19 percent lower risk of elderly mortality. In addition, a 1 standard deviation (SD) unit younger felt age, which refers to feeling approximately 9 years younger, was related to a 15 percent lower risk of mortality. On the other hand, a 1 standard deviation unit younger ideal age, which refers to wanting to be approximately 16 years younger, was associated with a 12 percent increased mortality risk. There was a relatively strong association between perceived control and elderly mortality: One standard deviation unit increase in perceived control was associated with a 23 percent reduction in mortality. Table 3 also shows the results from the stepwise proportional hazards models. Model 1 indicates that older age and being male were associated with an increased hazard of dying over the follow-up. Model 1 contributed to 11 percent explained variation in survival time. In Model 2, both lower levels of education and wealth were significantly associated with higher mortality risk, irrespective of age and gender. Taking age and gender into account, a one unit increase from lowest SES was associated with a 17 to 18 percent reduction in the hazard of elderly mortality. Adding SES explained an additional 2 percent of the total variation. Ideal and felt age discrepancies were added in Model 3, but the decrease in $-2 \log$ likelihood was not significant $\left(\chi^{2}=184,59 ; d f=6 ; p=0.140\right)$ indicating that adding SA did not significantly contribute to improved model fit over and above sociodemographic and SES characteristics. The lack of significant associations with mortality also implied lack of evidence for the mediating role of subjective age in the association between SES and mortality and limits the potentially mediating role of perceived control. In Model 4, lower perceived control was significantly associated with mortality in older adults. Individuals scoring 1 standard deviation higher on the PMS had a 20 percent reduction in mortality risk. Adding perceived control contributed to an additional 1.8 percent explained variation in survival time. The positive associations of higher education and wealth remained, however, statistically significant, suggesting independent associations of SES and perceived control with elderly mortality. The final full model, adjusting for physical health limitations, cigarette smoking, and partner status, yielded the association of education with mortality no longer statistically significant. These core confounders contributed to an additional 5 percent explained variation in longevity conditional upon survival to age 67 , summing up to a total of 20.2 percent explained variance. The association of higher levels of wealth and perceived control with reduced elderly mortality remained statistically significant, also after taking important confounders into account.

\section{DISCUSSION}

The findings from the current study did not support a mediating role of secondary or primary control strategies in the association between SES and elderly mortality. Rather, lower levels of 
TABLE 2 | Bivariate correlations (Pearson's r) between the study variables $(N=1,432)$.

\begin{tabular}{|c|c|c|c|c|c|c|c|c|c|c|c|}
\hline Variables & 1 & 2 & 3 & 4 & 5 & 6 & 7 & 8 & 9 & 10 & 11 \\
\hline 1. Chronological age & 1 & & & & & & & & & & \\
\hline 2. Perceived control & $-0.21 * *$ & 1 & & & & & & & & & \\
\hline 3. Felt age proportional discrepancy & $-0.08 * *$ & $0.12 * *$ & 1 & & & & & & & & \\
\hline 4. Ideal age proportional discrepancy & $0.08 * *$ & $-0.08 * *$ & $0.18 * *$ & 1 & & & & & & & \\
\hline 5. Education (1-3) & -0.01 & $0.11 * *$ & 0.00 & $-0.06 *$ & 1 & & & & & & \\
\hline 6. Wealth (1-4) & 0.05 & $0.08 * *$ & -0.04 & 0.01 & $0.31 * *$ & 1 & & & & & \\
\hline 7. Gender ( 0 = Man; 1 = Woman) & -0.00 & $-0.09 * *$ & 0.01 & $-0.19 * *$ & $-0.12 * *$ & $-0.24 * *$ & 1 & & & & \\
\hline $\begin{array}{l}\text { 8. Physical health problems }(0=\mathrm{No} \text {; } \\
1=\text { Yes })\end{array}$ & $0.11 * *$ & $-0.20 * *$ & $-0.07 * *$ & 0.04 & -0.05 & $-0.11 * *$ & $0.12 * *$ & 1 & & & \\
\hline 9. Cigarette smoking $(0=\mathrm{No} ; 1=$ Yes) & $-0.14 * *$ & -0.01 & -0.05 & 0.03 & $-0.09 * *$ & $-0.06 *$ & 0.03 & 0.01 & 1 & & \\
\hline 10. Partner status $(0=\mathrm{No} ; 1=\mathrm{Yes})$ & $-0.15 * *$ & $0.06 *$ & 0.03 & 0.03 & $0.10 * *$ & $-0.07 * *$ & $-0.29 * *$ & $-0.06 *$ & $-0.08 * *$ & 1 & \\
\hline 11. Deceased ( $0=$ No; $1=$ Yes $)$ & $0.30 * *$ & $-0.18 * *$ & $-0.07 * *$ & $0.06 *$ & $-0.08 * *$ & $-0.07 *$ & $-0.12 * *$ & $0.17 * *$ & $0.08 * *$ & $-0.08 * *$ & 1 \\
\hline
\end{tabular}

$* p<0.05 ; * * p<0.01$

wealth and perceived control independently predict increased elderly mortality over an 11-year period, after taking core determinants of (inequalities in) life expectancy into account. These findings underline the specific importance of structural conditions (wealth) and suggest the continued importance of (perceived) primary control capacity for longevity also after age 67. Although SA could not account for SES-related variability in life span among older Norwegians, our study showed that feeling younger and wanting to be an age closer to one's actual age were positively associated with perceived control. This is consistent with the LSD perspective that proposes SA as an important secondary control strategy in older adults. The main findings and study limitations are discussed below.

\section{The Importance of Accumulated Wealth for Mortality at Older Ages}

There is relatively limited research on wealth inequalities in mortality at older ages, partly because of a lack of accurate wealth data from household surveys (Bosworth, 2018). A strength of the current study is the availability of wealth data from the national public registers. Our findings thus contribute to knowledge generated from studies showing persisting wealth inequalities in mortality at older ages, after taking level of education into account (Demakakos et al., 2016; Attanasio and Nielsen, 2020; Zaninotto et al., 2020). Unlike education, wealth measures the accumulation of resources and assets over the life course. Low wealth likely indicates the detrimental effect of the accumulation of disadvantage over the life course and identifies a population at risk (Demakakos et al., 2016). Most research on the association of wealth and mortality stems from the United States, where explanations are geared toward socioeconomic differences in access to healthcare and insurance. Our findings suggest that the importance of wealth for elderly mortality also expands to other national contexts, in this case Norway, a country with an extensive welfare state comprising redistributive policies and universal social protection systems. After age 67, accumulated wealth may be a more accurate marker of SES affecting how older adults are facing challenges associated with advanced age, independent of perceived control. However, wealth and education contributed to explain only $2 \%$ of the total variation in elderly mortality, and associations with perceived control were weak. One position that explains this is "age-as-a-leveler" (Dupre, 2007), which suggests that SES inequalities in health are leveled out with increasing age because of mortality selection, in this case higher mortality among those with low education and low wealth before age 67 . The relatively weak associations may also reflect the substantial heterogeneity among older persons with low levels of education or wealth, underlining that not all older persons with a low SES can be labeled vulnerable or at risk.

\section{Psychological Pathways to Elderly Mortality}

Similar to previous studies (Bosma et al., 1999; Hall et al., 2010; Chipperfield et al., 2012; Infurna et al., 2013), the current study showed that perceived higher control contributed significantly to reduced elderly mortality over an 11-year follow-up. In terms of LSD theory, these findings support the importance of maintaining or enhancing primary control capacity in older adults (Kunzmann et al., 2002; Daatland and Hansen, 2007; Bercovitz et al., 2019), for example, by emphasizing elements of choice and personal responsibility or through motivational behavioral interventions targeting self-protection strategies (Hall et al., 2010). Such strategies may include goal disengagement, the importance of which is supported by our finding that larger ideal age discrepancies, that is, wanting to be increasingly younger than one's actual age, are associated with perceived lower control.

Unlike findings from studies including general populations (Bosma et al., 1999; Turiano et al., 2014), our findings did not suggest evidence for people with lower SES being more disadvantaged because of low perceived control or maladaptive SA. This may be due to SES differences in mortality being relatively smaller in older compared with middle-aged people. In addition, we did not find evidence for a direct association of subjective age perceptions with elderly mortality when taking age and gender into account. This may be considered puzzling, given that many studies have shown a robust association between similar measures of older subjective age and higher risk of 
TABLE 3 | Mortality risk in older adults (67+). Bivariate coefficients for and stepwise Cox proportional hazards regression analyses ( $N=1,432)$. Hazard Ratios (HR) and 95\% Confidence Intervals (Cl).

\begin{tabular}{|c|c|c|c|c|c|c|}
\hline \multirow{2}{*}{$\begin{array}{l}\text { Predictors (baseline } \\
\text { NorLAG2) }\end{array}$} & Unadjusted & $\begin{array}{l}\text { Model } 1 \text { Age, } \\
\text { gender }\end{array}$ & \multirow{2}{*}{$\begin{array}{l}\text { Model } 2 \text { SES } \\
\text { HR }(95 \% \mathrm{Cl})\end{array}$} & \multirow{2}{*}{$\begin{array}{l}\text { Model } 3 \text { SA } \\
\text { HR }(95 \% \mathrm{Cl})\end{array}$} & \multirow{2}{*}{$\begin{array}{l}\text { Model } 4 \text { Control } \\
\text { HR }(95 \% \mathrm{Cl})\end{array}$} & \multirow{2}{*}{$\begin{array}{l}\text { Model } 5 \text { Full } \\
\text { HR (95\% Cl) }\end{array}$} \\
\hline & HR $(95 \% \mathrm{Cl})$ & HR $(95 \% \mathrm{Cl})$ & & & & \\
\hline Education (1-3) & $0.81(0.70-0.94) * *$ & & $0.82(0.70-0.95) * *$ & $0.82(0.71-0.97)^{*}$ & $0.84(0.72-0.99) *$ & $0.88(0.75-1.03)$ \\
\hline Wealth (1-4) & $0.88(0.81-0.97)^{* *}$ & & $0.83(0.75-0.92) * * *$ & $0.83(0.75-0.92) * * *$ & $0.83(0.75-0.92) * * *$ & $0.82(0.74-0.91) * *$ \\
\hline $\begin{array}{l}\text { Felt age proportional } \\
\text { discrepancy (Z- score) }\end{array}$ & $0.85(0.76-0.96)^{* *}$ & & & $0.90(0.80-1.00)$ & $0.92(0.82-1.03)$ & $0.96(0.86-1.07)$ \\
\hline $\begin{array}{l}\text { Ideal age proportional } \\
\text { discrepancy (Z- score) }\end{array}$ & $1.12(1.01-1.24)^{*}$ & & & $1.03(0.93-1.14)$ & $1.01(0.91-1.12)$ & $0.99(0.89-1.10)$ \\
\hline $\begin{array}{l}\text { Perceived control } \\
\text { (Z-score) }\end{array}$ & $0.72(0.66-0.79) * * *$ & & & & $0.80(0.73-0.88) * * *$ & $0.83(0.75-0.92) * * *$ \\
\hline $\begin{array}{l}\text { Gender }(0=\text { Man; } \\
1=\text { Woman })\end{array}$ & & $0.62(0.50-0.76) * * *$ & $0.53(0.43-0.66) * * *$ & $0.54(0.43-0.687 * * *$ & $0.52(0.42-0.66) * * *$ & $0.43(0.34-0.54) * * *$ \\
\hline Chronological age & & $1.13(1.10-1.15) * * *$ & $1.13(1.11-1.16) * * *$ & $1.13(1.11-1.15) * * *$ & $1.12(1.10-1.14) * * *$ & $1.12(1.09-1.14) * * *$ \\
\hline $\begin{array}{l}\text { Physical health problems } \\
(0=\text { No; } 1=\text { Yes })\end{array}$ & & & & & & $1.84(1.47-2.29) * * *$ \\
\hline $\begin{array}{l}\text { Smoking cigarettes } \\
(0=\text { No; } 1=\text { Yes })\end{array}$ & & & & & & $1.74(1.34-2.25) * * *$ \\
\hline $\begin{array}{l}\text { Partner status }(0=\mathrm{No} \text {; } \\
1=\text { Yes })\end{array}$ & & & & & & $0.73(0.58-0.91) * *$ \\
\hline -2log likelihood & & 5084.093 & 5055.84 & 5051.95 & 5033.72 & 4978.78 \\
\hline$\Delta \chi^{2}$ & & & $28.3(2 d f)$ & $3.88(2 d f)$ & $18.24(1 d f)$ & $54.94(3 d f)$ \\
\hline
\end{tabular}

$* p<0.05 ; * * p<0.01 ; * * * p<0.001$

mortality across adulthood (Kotter-Gruhn et al., 2009; Rippon and Steptoe, 2015; Stephan et al., 2018). The proportional discrepancy score for felt age in our study (0.12) was somewhat smaller than in the Midlife in the United States Survey (MIDUS; 0.16), where a similar measure of SA was used (Stephan et al., 2018). The adjusted HRs for mortality found in our sample were smaller compared to those in MIDUS, $10 \%$ versus $18 \%$ higher risk of mortality for $1 \mathrm{SD}$ older subjective age. Possible explanations for the limited role of SA in the present study may therefore be related to a smaller sample size or that that the associations of SA with mortality are found to be stronger in countries without an extensive welfare state (Barrett, 2003; Westerhof et al., 2012, 2014).

\section{Limitations}

Our findings are based on a representative sample of community-dwelling older Norwegians and should generalize to the broader population of older non-institutionalized adults (Veenstra et al., 2021). However, greater non-response among those with poor health and lower education may have affected the findings of the current study by underestimating core associations, for example, between education and mortality. Our study had a relatively long timespan and did not include repeated measurements between baseline and the follow-up endpoint. We were therefore not able to include time-varying predictors in studying patterns of elderly mortality, which may be important for detecting short-term associations of SA. In addition, our findings addressed all-cause mortality and we had no data on causes of death. Moreover, the significant contribution of perceived lower control to elderly mortality may also reflect a naturalistic explanation, in that, closer to death, control capacity is reduced and a realistic appraisal of one's situation with regard to controllability is warranted, which results in lower scores on measures of domain-general perceived control capacity such as the PMS. Our study did not include measures of domain-specific perceived control. People may perceive control in some major domains of life but not in others. Neither did our study include measures of motivational investment, which would have been more in line with Heckausen's motivational theory of life span development (Heckhausen et al., 2019).

\section{CONCLUSION}

Perceived control and accumulated wealth contribute independently to mortality in adults aged 67 years and older, after taking core determinants of (inequalities in) life expectancy into account. Our findings add to research showing that perceived control is an integral component of healthy aging (Lachman, 2006; Heckhausen et al., 2019) and contribute to the knowledgebase on socioeconomic inequalities in the second half of life by demonstrating persistent wealth inequalities in elderly mortality in a country with an extensive welfare state. Future research is needed to assess in more detail how wealth and perceived control complement each other in contributing to healthy aging and longevity, for example, by longitudinal research including the role of significant life events in the second half of life in different welfare state contexts. Important questions for future research on aging should also include the end of life and provide updated knowledge on how levels of perceived control may contribute to regulate emotions, reduce anxiety, fear of death, and facilitate processes of reconciliation in older adults. 


\section{DATA AVAILABILITY STATEMENT}

Publicly available datasets were analyzed in this study. This data can be found here: https://norlag.nsd.no/.

\section{ETHICS STATEMENT}

Ethical review and approval was not required for the study on human participants in accordance with the local legislation and institutional requirements. Written informed consent for participation was not required for this study in accordance with the national legislation and the institutional requirements.

\section{AUTHOR CONTRIBUTIONS}

MV and SD conceived the idea for the study. MV, SD, and GL contributed to its design. MV prepared, analyzed, and interpreted the data and produced the first draft of the manuscript. $\mathrm{SD}$ and GL provided feedback on earlier drafts. All

\section{REFERENCES}

Abramson, C. M., and Portacolone, E. (2017). What is new with old? What old age teaches us about inequality and stratification. Sociol. Compass 11:e12450. doi: 10.1111/soc4.12450

Aburto, J. M., Villavicencio, F., Basellini, U., Kjaergaard, S., and Vaupel, J. W. (2020). Dynamics of life expectancy and life span equality. Proc. Natl. Acad. Sci. U. S. A. 117, 5250-5259. doi: 10.1073/pnas.1915884117

Attanasio, O., and Nielsen, T. H. (2020). Economic Resources, Mortality and Inequality. (CEBI Working Paper Series, Issue; January 13, 2020).

Bailis, D. S., Chipperfield, J. G., and Perry, R. P. (2005). Optimistic social comparisons of older adults low in primary control: a prospective analysis of hospitalization and mortality. Health Psychol. 24, 393-401. doi: 10.1037/0278-6133.24.4.393

Barak, B., and Stern, B. (1986). Subjective age correlates: a research note. Gerontologist 26, 571-578. doi: 10.1093/geront/26.5.571

Barrett, A. E. (2003). Socioeconomic status and age identity: The role of dimensions of health in the subjective construction of age. J. Gerontol. Series B 58, S101-S109. doi: 10.1093/geronb/58.2.S101

Bercovitz, K. E., Ngnoumen, C., and Langer, E. J. (2019). "Personal control and successful aging," in The Cambridge Handbook of Successful Aging. eds. A. Benetos, J.-M. Robine and R. Fernández-Ballesteros (United Kingdom: Cambridge University Press), 384-400.

Blau, Z. S. (1956). Changes in status and age identification. Am. Sociol. Rev. 21, 198-203. doi: $10.2307 / 2088522$

Bosma, H., Schrijvers, C., and Mackenbach, J. P. (1999). Socioeconomic inequalities in mortality and importance of perceived control: cohort study. BMJ 319, 1469-1470. doi: 10.1136/bmj.319.7223.1469

Bosworth, B. (2018). Increasing disparities in mortality by socioeconomic status. Demo. Aging 39, 237-251. doi: 10.1146/annurev-publhealth-040617-014615

Chipperfield, J. G., Newall, N. E., Perry, R. P., Stewart, T. L., Bailis, D. S., and Ruthig, J. C. (2012). Sense of control in late life: health and survival implications. Personal. Soc. Psychol. Bull. 38, 1081-1092. doi: 10.1177/0146167212444758

Chipperfield, J. G., Perry, R. P., and Menec, V. H. (1999). Primary and secondary control-enhancing strategies: implications for health in later life. J. Aging Health 11, 517-539. doi: 10.1177/089826439901100403

Demakakos, P., Biddulph, J. P., Bobak, M., and Marmot, M. G. (2016). Wealth and mortality at older ages: a prospective cohort study. J. Epidemiol. Community Health 70, 346-353. doi: 10.1136/jech-2015-206173

Diehl, M., Wahl, H. W., Barrett, A. E., Brothers, A. F., Miche, M., Montepare, J. M., et al. (2014). Awareness of aging: theoretical considerations on an emerging concept. Dev. Rev. 34, 93-113. doi: 10.1016/j.dr.2014.01.001 authors approved the final version of the manuscript to be published.

\section{FUNDING}

The research presented here was carried out with financial support from the Research Council of Norway (Grant No. 301958).

\section{ACKNOWLEDGMENTS}

The NorLAG survey data collections have been financed by The Research Council of Norway, four Norwegian Government Ministries, The Norwegian Directorate of Health, The Norwegian State Housing Bank, Statistics Norway and NOVA at Oslo Metropolitan University. NorLAG data (doi:10.18712/norlag3_1) are part of the ACCESS Life Course infrastructure funded by the National Financing Initiative for Research Infrastructure at the Research Council of Norway (195403 and 269920).

Dupre, M. E. (2007). Educational differences in age-related patterns of disease reconsidering the cumulative disadvantage and age-as-Leveler hypotheses. J. Health Soc. Behav. 48, 1-15. doi: 10.1177/002214650704800101

Daatland, S. O. (2007). "Age identifications," in Geropsychology: European Perspectives for an Aging World. ed. R. Fernández-Ballesteros (Germany: Hogrefe and Huber), 31-48.

Daatland, S. O., and Hansen, T. (2007). "Well-being, control and ageing: An empirical assessment," in Quality of Life in Old Age: International and MultiDisciplinary Perspectives. eds. H. Mollenkopf and A. Walker (Netherlands: Springer), 33-47.

Elstad, J. I. (1998). The psycho-social perspective on social inequalities in health. Sociol. Health Illness 20, 598-618. doi: 10.1111/1467-9566.00121

Hall, N. C., Chipperfield, J. G., Heckhausen, J., and Perry, R. P. (2010). Control striving in older adults with serious health problems: A 9-year longitudinal study of survival, health, and well-being. Psychol. Aging 25, 432-445. doi: $10.1037 / \mathrm{a} 0019278$

Heckhausen, J. (1997). Developmental regulation across adulthood: primary and secondary control of age-related challenges. Dev. Psychol. 33, 176-187. doi: 10.1037/0012-1649.33.1.176

Heckhausen, J., Wrosch, C., and Schulz, R. (2010). A motivational theory of life-span development. Psychol. Rev. 117, 32-60. doi: 10.1037/a0017668

Heckhausen, J., Wrosch, C., and Schulz, R. (2019). Agency and motivation in adulthood and old age. Annu. Rev. Psychol. 70, 191-217. doi: 10.1146/ annurev-psych-010418-103043

Hubley, A. M., and Hultsci, D. F. (1994). The relationship of personality-trait variables to subjective age identity in older adults. Res. Aging 16, 415-439. doi: 10.1177/0164027594164005

Infurna, F. J., Ram, N., and Gerstorf, D. (2013). Level and change in perceived control predict 19-year mortality: findings from the Americans' changing lives study. Dev. Psychol. 49, 1833-1847. doi: 10.1037/a0031041

Kastenbaum, R., Derbin, V., Sabatini, P., and Artt, S. (1972). "The ages of me": Toward personal and interpersonal definitions of functional aging. Aging Human Develop. 3, 197-211. doi: 10.2190/TUJR-WTXK-866Q-8QU7

Kaufman, G., and Elder, G. H. (2002). Revisiting age identity - A research note. J. Aging Stud. 16, 169-176. doi: 10.1016/S0890-4065(02)00042-7

Keyes, C. L. M., and Westerhof, G. J. (2012). Chronological and subjective age differences in flourishing mental health and major depressive episode. Aging Ment. Health 16, 67-74. doi: 10.1080/13607863.2011.596811

Kinge, J. M., Modalsli, J. H., Øverland, S., Gjessing, H. K., Tollånes, M. C., Knudsen, A. K., et al. (2019). Association of Household Income With Life 
Expectancy and Cause-Specific Mortality in Norway, 2005-2015. JAMA 321, 1916-1925. doi: 10.1001/jama.2019.4329

Kleinspehn-Ammerlahn, A., Kotter-Gruhn, D., and Smith, J. (2008). Selfperceptions of aging: do subjective age and satisfaction with aging change during old age? J. Gerontol. B Psychol. Sci. Soc. Sci. 63, P377-P385. doi: 10.1093/geronb/63.6.P377

Kornadt, A. E., Hess, T. M., Voss, P., and Rothermund, K. (2018). Subjective age Across the life span: A differentiated, longitudinal approach. J. Gerontol. B Psychol. Sci. Soc. Sci. 73, 767-777. doi: 10.1093/geronb/gbw072

Kotter-Gruhn, D., Kleinspehn-Ammerlahn, A., Gerstorf, D., and Smith, J. (2009). Self-perceptions of aging predict mortality and change With approaching death: 16-year longitudinal results From the Berlin aging study. Psychol. Aging 24, 654-667. doi: 10.1037/a0016510

Kotter-Gruhn, D., Kornadt, A. E., and Stephan, Y. (2016). Looking Beyond chronological age: current knowledge and future directions in the study of subjective age. Gerontology 62, 86-93. doi: 10.1159/000438671

Kunzmann, U., Little, T., and Smith, J. (2002). Perceiving control: A doubleedged sword in old age. J. Gerontol. Psychol. Sci. Soc. Sci. 57, P484-P491. doi: $10.1093 /$ geronb/57.6.P484

Lachman, M. E. (2006). Perceived control over aging-related declines: adaptive beliefs and behaviors. Curr. Dir. Psychol. Sci. 15, 282-286. doi: 10.1111/j.1467-8721. 2006.00453.x

Lachman, M. E., and Weaver, S. L. (1998). The sense of control as a moderator of social class differences in health and well-being. J. Pers. Soc. Psychol. 74, 763-773. doi: 10.1037/0022-3514.74.3.763

Levy, B. R. (2009). Stereotype embodiment: A psychosocial approach to aging. Curr. Dir. Psychol. Sci. 18, 332-336. doi: 10.1111/j.1467-8721.2009.01662.x

Levy, B. R., Slade, M. D., Kunkel, S. R., and Kasl, S. V. (2002). Longevity increased by positive self-perceptions of aging. J. Pers. Soc. Psychol. 83, 261-270. doi: 10.1037/0022-3514.83.2.261

Mackenbach, J. P., Valverde, J. R., Bopp, M., Bronnum-Hansen, H., Deboosere, P., Kalediene, R., et al. (2019). Determinants of inequalities in life expectancy: an international comparative study of eight risk factors. Lancet Public Health 4, e529-e537. doi: 10.1016/S2468-2667(19)30147-1

Maier, H., and Smith, J. (1999). Psychological predictors of mortality in old age. The journals of gerontology. Psychol. Sci. Soc. Sci. 54, P44-P54. doi: 10.1093/geronb/54b.1.p44

Mirowsky, J., and Ross, C. E. (2007). Life course trajectories of perceived control and their relationship to education. Am. J. Sociol. 112, 1339-1382. doi: $10.1086 / 511800$

Montepare, J. M., and Lachman, M. E. (1989). "You're only as old as you feel": self-perceptions of age, fears of aging, and life satisfaction from adolescence to old age. Psychol. Aging 4, 73-78. doi: 10.1037/0882-7974.4.1.73

Murtin, F., Mackenbach, J., Jasilionis, D., and d'Ercole, M. M. (2017). Inequalities in longevity by education in OECD countries. OECD Statistics Working Papers; January 10, 2017.

OECD. (2017). Preventing Ageing Unequally. Paris: OECD Publishing.

Pearlin, L. I., Lieberman, M. A., Menaghan, E. G., and Mullan, J. T. (1981). The stress process. J. Health Soc. Behav. 22, 337-356. doi: 10.2307/2136676

Pearlin, L. I., and Schooler, C. (1978). The structure of coping. J. Health Soc. Behav. 19, 2-21. doi: 10.2307/2136319

Permanyer, I., and Scholl, N. (2019). Global trends in lifespan inequality: 1950-2015. PLoS One 14:e215742. doi: 10.1371/journal.pone. 0215742

Phelan, J. C., Link, B. G., and Tehranifar, P. (2010). Social conditions as fundamental causes of health inequalities: theory, evidence, and policy implications. J. Health Soc. Behav. 51 (Suppl.), S28-S40. doi:10.1177/0022146510383498

Rippon, I., and Steptoe, A. (2015). Feeling old vs being old: associations between self-perceived age and mortality. JAMA Intern. Med. 175, 307-309. doi: 10.1001/jamainternmed.2014.6580

Robinson, S. A., and Lachman, M. E. (2017). Perceived control and aging: A mini-review and directions for future research. Gerontology 63, 435-442. doi: $10.1159 / 000468540$

Schulz, R., and Heckhausen, J. (1996). A life span model of successful aging. Am. Psychol. 51, 702-714. doi: 10.1037/0003-066X.51.7.702

Settersten, R. A., and Hagestad, G. O. (2015). Subjective Aging and New Complexities of the Life Course. United States: Springer Publishing Co.
Settersten, R. A., and Mayer, K. U. (1997). The measurement of age, age structuring, and the life course. Annu. Rev. Sociol. 23, 233-261. doi: 10.1146/ annurev.soc.23.1.233

Shane, J., Hamm, J., and Heckhausen, J. (2019). Subjective age at work: feeling younger or older Than One's actual age predicts perceived control and motivation at work. Work Aging Retirement 5, 323-332. doi: 10.1093/workar/waz013

Slagsvold, B., and Sørensen, A. (2013). Changes in sense of control in the second half of life: results from a 5-year panel study. Int. J. Aging Hum. Dev. 77, 289-308. doi: 10.2190/AG.77.4.b

Stephan, Y., Sutin, A. R., and Terracciano, A. (2018). Subjective age and mortality in three longitudinal samples. Psychosom. Med. 80, 659-664. doi: 10.1097/ PSY.0000000000000613

Thompson, S. C., Thomas, C., Rickabaugh, C. A., Tantamjarik, P., Otsuki, T., Pan, D., et al. (1998). Primary and secondary control over age-related changes in physical appearance. J. Pers. 66, 583-605. doi: 10.1111/1467-6494.00025

Turiano, N. A., Chapman, B. P., Agrigoroaei, S., Infurna, F. J., and Lachman, M. (2014). Perceived control reduces mortality risk at low, not high, education levels. Health Psychol. 33, 883-890. doi: 10.1037/hea0000022

Uotinen, V., Rantanen, T., and Suutama, T. (2005). Perceived age as a predictor of old age mortality: a 13-year prospective study. Age Ageing 34, 368-372. doi: 10.1093/ageing/afi091

Uotinen, V., Rantanen, T., Suutama, T., and Ruoppila, I. (2006). Change in subjective age among older people over an eight-year follow-up: 'getting older and feeling younger?'. Exp. Aging Res. 32, 381-393. doi: 10.1080/03610730600875759

Veenstra, M., Daatland, S. O., and Aartsen, M. (2020). The role of subjective age in sustaining wellbeing and health in the second half of life. Ageing Soc., 1-21. doi: 10.1017/S0144686X2000032X

Veenstra, M., Herlofson, K., Aartsen, M., Hansen, T., Hellevik, T., Henriksen, G., et al. (2021). Cohort profile: The Norwegian life course, ageing and generation study (NorLAG). Int. J. Epidemiol. 58, 728-729. doi: 10.1093/ije/dyaa280

Westerhof, G. J., Miche, M., Brothers, A. F., Barrett, A. E., Diehl, M., Montepare, J. M., et al. (2014). The influence of subjective aging on health and longevity: A meta-analysis of longitudinal data. Psychol. Aging 29, 793-802. doi: $10.1037 / \mathrm{a} 0038016$

Westerhof, G. J., Whitbourne, S. K., and Freeman, G. P. (2012). The aging self in a cultural context: the relation of conceptions of aging to identity processes and self-esteem in the United States and the Netherlands. J. Gerontol. B Psychol. Sci. Soc. Sci. 67, 52-60. doi: 10.1093/geronb/gbr075

Wolinsky, F. D., Wyrwich, K. W., Babu, A. N., Kroenke, K., and Tierney, W. M. (2003). Age, aging, and the sense of control among older adults: a longitudinal reconsideration. J. Gerontol. B Psychol. Sci. Soc. Sci. 58, S212-S220. doi: 10.1093/geronb/58.4.S212

Wrosch, C., Scheier, M. F., Miller, G. E., Schulz, R., and Carver, C. S. (2003). Adaptive self-regulation of unattainable goals: goal disengagement, goal reengagement, and subjective well-being. Personal. Soc. Psychol. Bull. 29, 1494-1508. doi: 10.1177/0146167203256921

Zaninotto, P., Batty, G. D., Stenholm, S., Kawachi, I., Hyde, M., Goldberg, M., et al. (2020). Socioeconomic inequalities in disability-free life expectancy in older people from England and the United States: A cross-national populationbased study. J. Gerontol. Series A 75, 906-913. doi: 10.1093/gerona/glz266

Conflict of Interest: The authors declare that the research was conducted in the absence of any commercial or financial relationships that could be construed as a potential conflict of interest.

Publisher's Note: All claims expressed in this article are solely those of the authors and do not necessarily represent those of their affiliated organizations, or those of the publisher, the editors and the reviewers. Any product that may be evaluated in this article, or claim that may be made by its manufacturer, is not guaranteed or endorsed by the publisher.

Copyright $\odot 2021$ Veenstra, Løset and Daatland. This is an open-access article distributed under the terms of the Creative Commons Attribution License (CC BY). The use, distribution or reproduction in other forums is permitted, provided the original author(s) and the copyright owner(s) are credited and that the original publication in this journal is cited, in accordance with accepted academic practice. No use, distribution or reproduction is permitted which does not comply with these terms. 